${ }^{1}$ Unidade de Medicina Interna e Serviço de Endocrinologia,

Faculdade de Medicina e

Hospital Universitário Clementino Fraga

Filho, Universidade Federal do Rio de

Janeiro, Rio de Janeiro, RJ, Brasil

${ }^{2}$ Unidade de Neuroendocrinologia,

Instituto Estadual do Cérebro Paulo

Niemeyer, Rio de Janeiro, RJ, Brasil

${ }^{3}$ Laboratório de Neuropatologia e Genética

Molecular, Instituto Estadual do Cérebro

Paulo Niemeyer, Rio de Janeiro, RJ, Brasil

${ }^{4}$ Divisão de Medicina Nuclear, Centro

de Imagem Copa D'Or e Hospital

Copa Star, Rio de Janeiro, RJ, Brasil

${ }^{5}$ Unidade de Cirurgia Torácica, Rede

D'Or São Paulo e Hospital Copa

Star, Rio de Janeiro, RJ, Brasil

${ }^{6}$ Divisão de Cirurgia Torácica, Instituto

do Câncer do Estado de São Paulo,

Hospital das Clínicas, Faculdade

de Medicina da Universidade de

São Paulo, São Paulo, SP, Brasil

${ }^{7}$ Divisão de Oncologia, Instituto

Oncoclínicas, Pesquisa e Educação,

Rio de Janeiro, RJ, Brasil

${ }^{8}$ Divisão de Patologia, Hospital das Clínicas

da Faculdade de Medicina da Universidade

de São Paulo, São Paulo, SP, Brasil

${ }^{9}$ Unidade de Cirurgia Torácica, Rede

D’Or Rio de Janeiro e Hospital Copa

Star, Rio de Janeiro, RJ, Brasil

${ }^{10}$ Unidade de Cirurgia Torácica, Pontifícia

Universidade Católica do Rio de

Janeiro, Rio de Janeiro, RJ, Brasil

Correspondence to:

Mônica R. Gadelha

Rua Professor Rodolpho

Paulo Rocco, 255, $9^{\circ}$ andar,

Setor 9F, Centro de Pesquisa

em Neuroendocrinologia,

Hospital Universitário Clementino

Fraga Filho

21941-913 - Rio de Janeiro, RJ, Brasil

mgadelha@hucff.ufrj.br

Received on Feb/20/2020

Accepted on Feb/15/2021

DOI: 10.20945/2359-3997000000346

\section{Cyclic ACTH-secreting thymic carcinoid: a case report and review of the literature}

Elisa B. Lamback ${ }^{1,2,3}$

https://orcid. org/0000-0002-6026-4329

Sérgio Altino de Almeida ${ }^{4}$

https://orcid.org/0000-0001-5667-5582

Ricardo Terra 5,6

https://orcid. org/0000-0002-5084-6704

Carlos Gil Ferreira ${ }^{7}$

https://orcid. org/0000-0002-7228-7018

Vera Luiza Capelozzi ${ }^{8}$

https://orcid. org/0000-0001-9732-5853

Rui Haddad 9.10

https://orcid. org/0000-0002-1288-3539

Mônica R. Gadelha' ${ }^{1,2,3}$

https://orcid. org/0000-0002-9250-3558

\section{SUMMARY}

Cyclic Cushing's syndrome (CS) due to thymic carcinoid is a rare disorder. We report a case of cyclic $\mathrm{CS}$ due to ectopic adrenocorticotropic hormone (ACTH)-secreting atypical thymic carcinoid tumor and reviewed similar cases published in the literature. Our patient had hypercortisolemia lasting approximately one month, followed by normal cortisol secretion, with relapse one year later. Histopathology revealed an atypical ACTH-positive thymic carcinoid. Ectopic CS can be derived from atypical thymic carcinoids, which can be aggressive tumors with early relapse, suggesting that this type of tumor probably needs aggressive treatment. Arch Endocrinol Metab. 2021;65(4):512-6

\section{INTRODUCTION}

Cushing's syndrome (CS) is a rare disorder $\checkmark$ characterized by inappropriately elevated secretion of cortisol (1). The syndrome has an estimated annual incidence of 0.2 to 5 per million persons (2). Most cases are caused by the overproduction of adrenocorticotrophic hormone (ACTH) by a pituitary corticotropinoma (2). Approximately $10 \%$ of CS cases result from the ectopic secretion of ACTH and are mainly derived from the foregut (larynx, thymus, lungs, stomach, duodenum and pancreas) $(3,4)$. Approximately 100 cases of CS arising from thymic neuroendocrine tumor (NET) have been described to date $(2,5)$. In rare cases, these thymic NET can be associated with cyclic CS (1).

We report a case of cyclic CS caused by a thymic NET and review similar cases published in the literature.

\section{CASE REPORT}

A 32-year-old Caucasian man presented with sudden and unexplained weight gain (nine kilograms in a month), decreased libido, arterial hypertension and acne at 30 years of age, which resolved spontaneously. One year later, he developed the same rapid-onset signs and symptoms, along with severe anxiety and panic attacks that required 
clonazepam treatment. At this time, the patient was referred to our institution, and we noted in retrospect that he had been investigated for decreased libido at the age of 29 years, being diagnosed and treated for central hypogonadism [total testosterone: $17 \mathrm{l} \mathrm{ng} / \mathrm{dL}$ [reference value (RV): 220-819; FSH: $5.2 \mathrm{mUI} / \mathrm{mL}(\mathrm{RV}: 1.5-12.4)$; LH: $3.5 \mathrm{mUI} / \mathrm{mL}$ (RV: 1.7-8.6); prolactin: $7.3 \mathrm{ng} / \mathrm{mL}$ (RV: 2.0-15.2)] with no further investigation. Physical examination revealed a typical cushingoid appearance, with facial plethora, moon face, central obesity, acne on his thighs, arterial hypertension and mild tachycardia. Cushing's syndrome was investigated, and biochemical assessment was compatible with ACTH-dependent CS: urinary free cortisol (UFC): $8077.5 \mathrm{mcg} / 24$ hours (RV: 2l-11l); 11 p.m. salivary cortisol: $8.3 \mathrm{mcg} / \mathrm{dL}$ (RV: <0.2); ACTH: 178 and $264 \mathrm{pg} / \mathrm{mL}(\mathrm{RV}:<46)$; 8 a.m. basal cortisol: $>60$ and $119.1 \mathrm{mcg} / \mathrm{dL}$. The dehydroepiandrosterone sulfate level was $1947 \mathrm{mcg} /$ dL (RV: 99-449), and the potassium level was normal at $4.6 \mathrm{mEq} / \mathrm{L}$ (RV: $3.5-5.3)$. He also showed central hypogonadism: total testosterone: $199 \mathrm{ng} / \mathrm{dL}$ (RV: 220-819); FSH: 2.1 mUI/mL (RV: 1.5-12.4); LH: 1.9 $\mathrm{mUI} / \mathrm{mL}$ (RV: 1.7-8.6).

No pituitary lesion was observed on magnetic resonance imaging (MRI). Bilateral inferior petrosal sinus sampling (BIPSS) demonstrated an ectopic origin for the hypercortisolemia (the ratio between central and peripheral ACTH was 1.2 at baseline and 2.3 after $10 \mathrm{mcg}$ of endovenous desmopressin). BIPSS was performed when the patient was likely exciting the active phase and entering normocortisolemia, as suggested by 8 a.m. basal cortisol value of $14.6 \mathrm{mcg} / \mathrm{dL}$ and still increased ACTH levels of $54.9 \mathrm{pg} / \mathrm{mL}$ measured six days after the biochemical confirmation of ACTH-dependent CS as stated above. UFC was not measured on the day of BIPSS. Even done at this stage, BIPSS was compatible with an ectopic origin (the gradient between central and peripheral ACTH was $<2$ at baseline and $<3$ after desmopressin). Computed tomography (CT) of the chest revealed an anterior mediastinal mass suggesting a thymic lesion (Figure 1). Octreotide receptor scintigraphy (octreoscan) demonstrated increased uptake of the tracer in the anterior mediastinum. The patient showed no evidence of carcinoid syndrome. He had normocalcemia, a normal chromogranin A level of $2.4 \mathrm{nmol} / \mathrm{L}(\mathrm{RV}:<3.0)$ and a negative family history of multiple endocrine neoplasia type l (MENl).

Similar to the previous episode, the signs and symptoms of CS resolved spontaneously after 30 to 40 days, with significant weight loss of $10.5 \mathrm{~kg}$ in this period and the 8 a.m. cortisol levels decreasing to 10.3 $\mathrm{mcg} / \mathrm{dL}$, suggesting cyclic CS. He showed no clinical or biochemical evidence of adrenal insufficiency. The central hypogonadism at the age of 29 years was attributed to inhibition of the hypothalamus-pituitarygonadal axis due to the hypercortisolemia that was likely already present at this age.

Robotic thymectomy was performed with a surgical description of complete tumor removal. The surgical specimen showed a tumor of $1.5 \mathrm{~cm}$ and several carcinoid tumorlets $(<1 \mathrm{~cm})$ in the surrounding abundant fat (Figure 2). Microscopically, the tumor was comprised of uniform cells with nested, trabecular, and rosette-like growth patterns. The polygonal tumor cells had moderate eosinophilic granular cytoplasm, round to oval nuclei, "salt and pepper" chromatin and inconspicuous nucleoli (Figure 3A). Large zones of necrosis were present, and the mitotic count varied from 4 to 6 mitoses $/ \mathrm{mm}^{2}$. Immunohistochemistry of the tumor samples was positive for CD56, chromogranin A, synaptophysin, and ACTH, and the Ki-67 index greater than 35\% (Figures 3B-D).

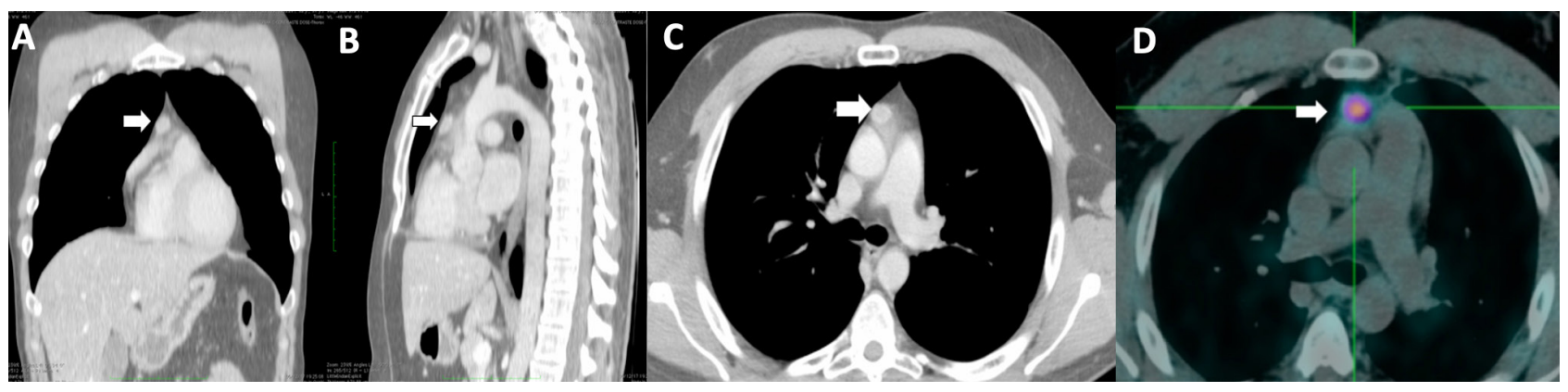

Figure 1. Chest computed tomography scan in the coronal $(\mathbf{A})$, sagittal $(\mathbf{B})$ and axial $(\mathbf{C})$ views showing a $2.0 \times 1.1 \times 1.4 \mathrm{~cm}$ tumor in the anterior mediastinum (arrows) and ${ }^{68} \mathrm{Ga}-\mathrm{DOTATOC}-\mathrm{PET}$ CT scan in the axial view (D) exhibiting focal radiotracer uptake in the anterior mediastinum (SUVmax = $6.7 / 15 \times 11 \mathrm{~mm})$. 


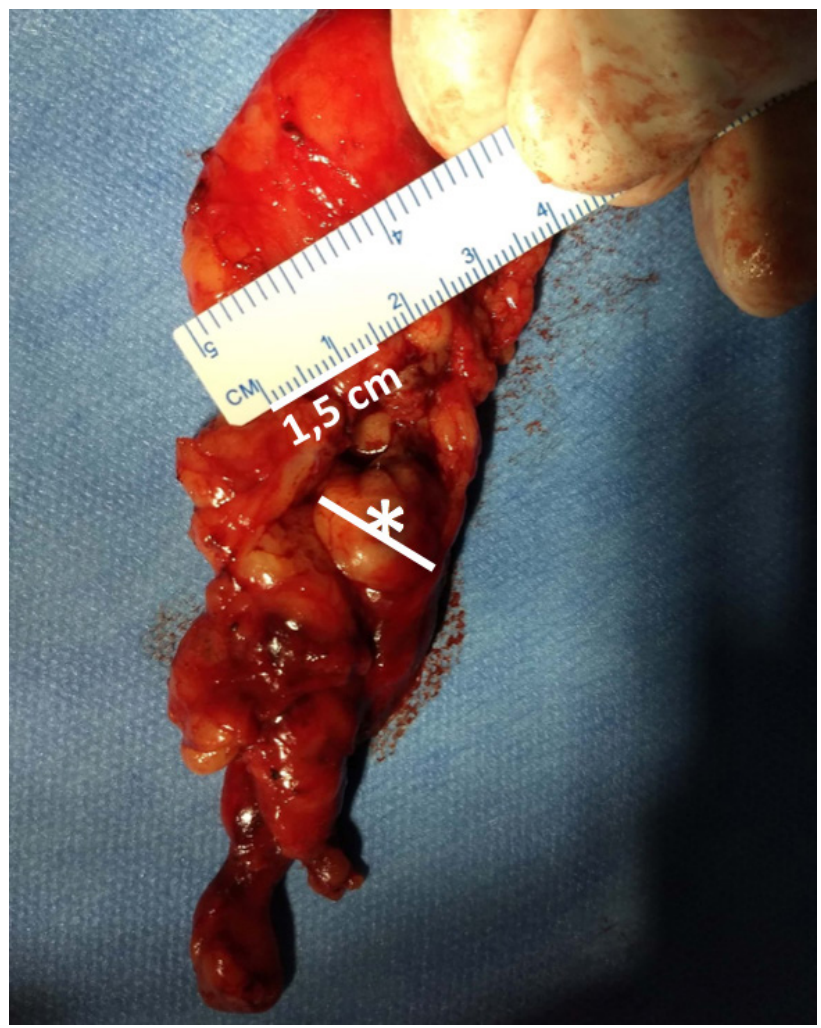

Figure 2. Surgical specimen with the tumor $\left(^{*}\right)$ measuring $1.5 \mathrm{~cm}$ with the thymic remnant showing several carcinoid tumorlets in the surrounding abundant fat.
On postoperative assessment, the patient required glucocorticoid coverage for a short period ( 1.5 months). The ACTH level was normalized to $43.6 \mathrm{pg} / \mathrm{mL}$. After three months of surgery, he had normal free urinary cortisol and 11 p.m. salivary cortisol but nonsuppression in an overnight dexamethasone suppression test [serum cortisol: $2.6 \mathrm{mcg} / \mathrm{dL}(\mathrm{RV}:<1.8)]$. The chromogranin A levels increased to $3.3 \mathrm{nmol} / \mathrm{L}(\mathrm{RV}$ : $<3.0)$, and ACTH increased to $71.6 \mathrm{pg} / \mathrm{mL}$ four months after surgery. At this time, the ${ }^{68} \mathrm{Ga}$-DOTATOC-PET CT scans demonstrated focal uptake in the anterior mediastinum (Figure 1), with mild radiotracer uptake in the same location as ${ }^{18} \mathrm{~F}$ FDG-PET CT. Although the patient had undergone complete surgical resection and remained asymptomatic, an increase in ACTH, chromogranin A and focal uptake in PET CT scans may indicate early relapse of an aggressive tumor. $\mathrm{He}$ remains on hypertensive medications, and has normal glycemic levels and a normal bone mineral density.

Considering the above findings, the patient was diagnosed with cyclic CS due to ACTH-secreting atypical thymic carcinoid based on the 2015 World Health Organization classification for neuroendocrine neoplasms.

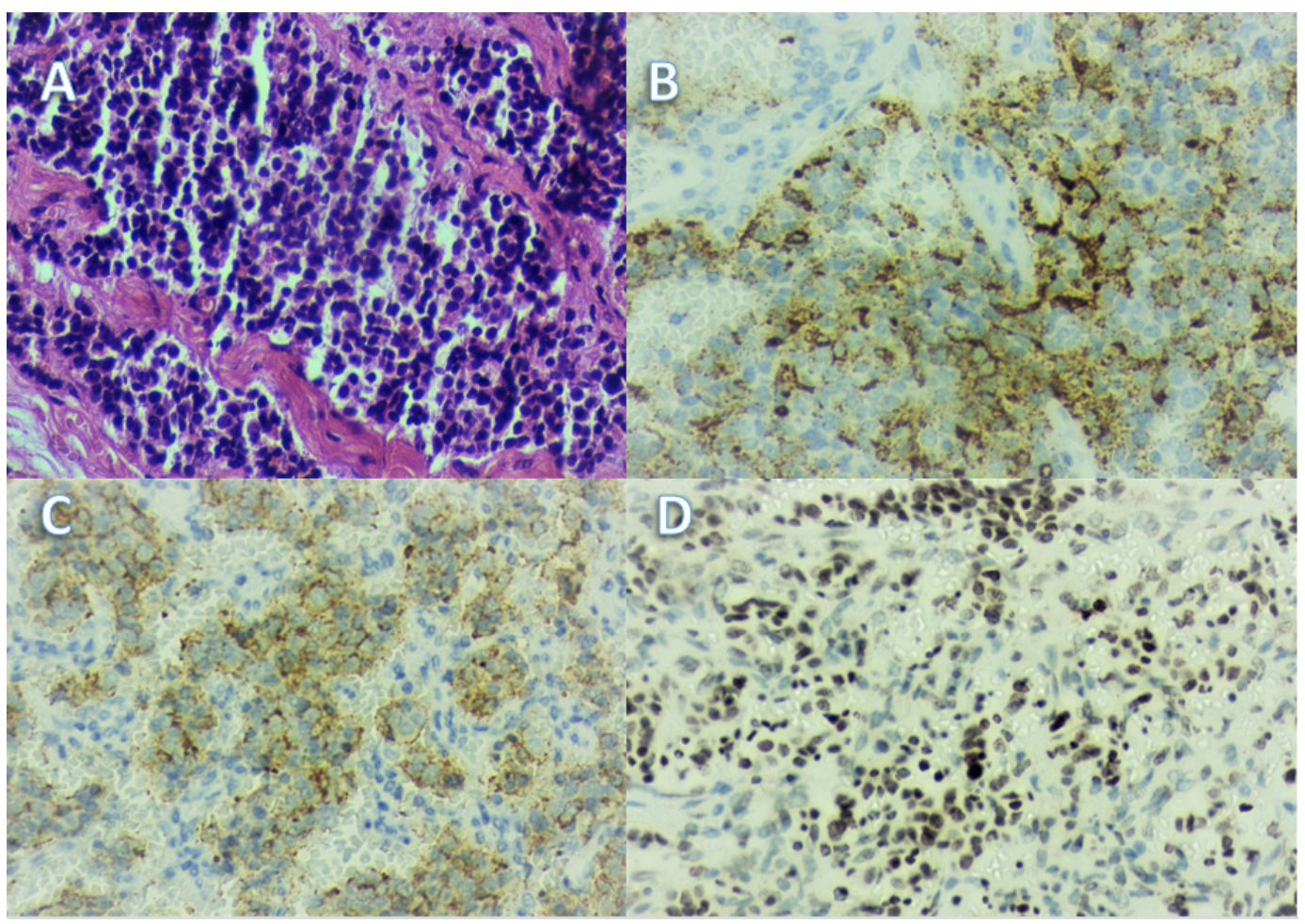

Figure 3. Histopathology of atypical thymic carcinoid. (A) Hematoxylin-eosin staining, $\times 200$, showing a solid and trabecular growth pattern among a delicate vascularized fibroconjunctival stroma; (B) Immunohistochemistry, $\times 200$, showing granular membranous ACTH staining; (C) Immunohistochemistry, $\times 200$, showing strong membranous chromogranin A staining; (D) Immunohistochemistry, $\times 200$, showing a high Ki67 proliferation index. 


\section{DISCUSSION}

We report a case of a male patient who presented with rapid-onset symptoms suggestive of hypercortisolemia that occurred during cycles that lasted approximately one month and relapsed every year for two years before the diagnosis of ectopic CS due to atypical thymic carcinoid. Approximately 100 cases describing CS resulting from ACTH secretion from thymic tumors have been reported in the literature, with fewer than 10 cases of cyclic CS due to ectopic ACTH secretion from a thymic NET (1,5-11).

Thymic NET are rare tumors with an annual incidence of 0.07 to 0.18 per million persons, with higher rates in Caucasians and male individuals (12). However, thymic ACTH-producing NET exhibit no gender preference and are usually diagnosed in early adulthood (21-35 years of age) (13). Functionally active tumors are seen in one-third to half of cases (13). Thymic carcinoids are associated with MEN 1 in up to $25 \%$ of cases (13).

In ectopic ACTH secretion, the ACTH plasma levels are usually very high, as observed in our case (1). Because most NET express somatostatin receptors, octreotide receptor scintigraphy (octreoscan) or PET CT with ${ }^{68}$ Gallium-labeled somatostatin analogs can be used to evaluate these patients, including in cases of ectopic ACTH-secreting tumors (14-16).

NET produce biogenic amines such as serotonin which may lead to carcinoid syndrome. NET originate from one of three portions of the primitive gut: foregut, midgut and hindgut. Thymic NET are foregut tumors, which have lower serotonin metabolism than midgut tumors, reflecting a low frequency of carcinoid syndrome in these patients, as observed in our case (1).

Patients with CS (from different etiologies) have episodic cortisol secretion (17). However, in a small subset of CS patients, highly variable levels of glucocorticoid secretion can occur. Episodes of hypercortisolemia interspaced with periods of normocortisolemia (or adrenal insufficiency) are known as cyclic CS (1). Adrenal insufficiency can also be observed, but was not seen in our case, probably because of the short cycle length. In cyclic CS, rhythmic fluctuations in ACTH secretion occur and result in more or less predictable cyclic variation in adrenal steroid production (18). The cycle length usually lasts one month and the intercyclic phase is prolonged in ectopic secretion of ACTH, as seen in our case (1).
Meinardi and cols. (1) reviewed 65 cases of cyclic CS cases. Most of the cases were due to Cushing's disease (CD), followed by the ectopic secretion of ACTH in $26 \%$ of cases. Considering that approximately $10 \%$ of CS cases are due to ectopic ACTH secretion, cyclic CS seems to occur more frequently in patients with ectopic ACTH secretion (1).

Based on literature reports of thymic NET causing cyclic CS published to date, the epidemiology is similar to thymic NET causing CS. The diagnosis usually occurs in early adulthood (20-43 years old), with no gender predilection $(1,5-9,11,13)$. Nevertheless, one case was described in a 7-year-old child (10). CS cycles may last days or months or are seasonal, as described by Trott and cols. (5). Additionally, symptoms of hypercortisolemia may not be typical because of the cyclic nature of the ACTH production. Furthermore, hypokalemia and osteoporosis, which are more frequent in ectopic CS, are not always present in cyclic CS and was not observed in our case (3). Nonetheless, cortisol-induced comorbidities should be monitored regularly. Cyclic CS also seems to cause more psychiatric disturbances than noncyclic CS, as observed in our case.

Cyclic CS is difficult to diagnose, requiring clinical suspicion and repeated testing. Dynamic testing is often inconclusive due to unsustained hypercortisolemia. The mechanism underlying cyclic CS remains unclear. A proposed explanation would be episodes of spontaneous tumor hemorrhage or cyclic growth and apoptosis of ACTH-secreting tumor cells $(19,20)$.

The 2015 WHO classification of thymic neuroendocrine tumors is generic but accurate, and the lesions are classified into three grades according to the mitotic count and presence of necrosis (21). Low-grade (typical carcinoid) lesions have 2 or fewer mitotic counts and no necrosis, intermediate-grade (atypical carcinoid) lesions have 2-10 mitotic counts and foci of necrosis, and high-grade (large cell neuroendocrine carcinoma and small cell carcinoma) lesions have more than 10 mitotic counts and the presence of necrosis. The distinction between an atypical neuroendocrine tumor (AC) and a large cell neuroendocrine carcinoma (LCNEC) is difficult based solely on the 2015 WHO pathological classification. Other pathological classifications and clinicopathological correlations are required. Applying the Ki-67-based ENETS classification, which shows that the $\mathrm{Ki}-67$ index of AC varies on average from $1 \%$ to $18.8 \%$ and that of LCNEC varies from $16 \%$ to $90 \%$, our case would be considered LCNEC $(22,23)$. However, 
based on early relapse, mitotic count and high Ki-67 index, the tumor was classified as overlapping between $\mathrm{AC}$ and LCNEC and considered an aggressive atypical neuroendocrine tumor.

Surgical treatment, with complete tumor removal, is the treatment of choice. Despite aggressive treatment, thymic NET have a poor prognosis. The ten-year survival rate is $38 \%$, with worse outcomes in patients with CS (24-26). The role of chemotherapy has not been well established because the low number of studied patients limits its assessment (1).

Despite the resolution of hypercortisolemia with the resection of thymic tumors in our case, the patient had an ACTH level in the upper limit of the normal range and a nonsuppression response to the overnight dexamethasone suppression test, which could represent an unfavorable prognosis.

In conclusion, cyclic CS represents a clinical challenge requiring clinical suspicion. Ectopic CS can be derived from atypical ACTH-producing thymic carcinoids, which can relapse early, even after complete surgical removal. This outcome shows that this type of aggressive disease likely requires aggressive treatment.

Disclosure: no potential conflict of interest relevant to this article was reported.

\section{REFERENCES}

1. Meinardi JR, Wolffenbuttel BH, Dullaart RP. Cyclic Cushing's syndrome: a clinical challenge. Eur J Endocrinol. 2007;157(3):24554.

2. Lacroix A, Feelders RA, Stratakis CA, Nieman LK. Cushing's syndrome. Lancet. 2015;386(9996):913-27.

3. Young J, Haissaguerre M, Viera-Pinto O, Chabre O, Baudin E, Tabarin A. Management Of Endocrine Disease: Cushing's syndrome due to ectopic ACTH secretion: an expert operational opinion. Eur J Endocrinol. 2020;182(4):R29-R58.

4. Rindi G, Klimstra DS, Abedi-Ardekani B, Asa SL, Bosman FT, Brambilla $E$, et al. A common classification framework for neuroendocrine neoplasms: an International Agency for Research on Cancer (IARC) and World Health Organization (WHO) expert consensus proposal. Mod Pathol. 2018;31(12):1770-86.

5. Trott MJ, Farah G, Stokes VJ, Wang LM, Grossman AB. A thymic neuroendocrine tumour in a young female: a rare cause of relapsing and remitting Cushing's syndrome. Endocrinol Diabetes Metab Case Rep. 2016;2016:160018.

6. Ilias I, Torpy DJ, Pacak K, Mullen N, Wesley RA, Nieman LK. Cushing's syndrome due to ectopic corticotropin secretion: twenty years' experience at the National Institutes of Health. J Clin Endocrinol Metab. 2005;90(8):4955-62.

7. Neary NM, Lopez-Chavez A, Abel BS, Boyce AM, Schaub N, Kwong $\mathrm{K}$, et al. Neuroendocrine ACTH-producing tumor of the thymus--experience with 12 patients over 25 years. J Clin Endocrinol Metab. 2012;97(7):2223-30.
8. Estopinan V, Varela C, Riobo P, Dominguez JR, Sancho J. Ectopic Cushing's syndrome with periodic hormonogenesis--a case suggesting a pathogenetic mechanism. Postgrad Med J. 1987;63(744):887-9.

9. Walker AB, Leese GP, Vora JP. Diagnostic difficulties in periodic Cushing's syndrome. Postgrad Med J. 1997;73(861):426-8.

10. Qiang Mi M-ZY, Yi-Jin Gao, Jing-Yan Tang, Yu-Min Zhong, WenXiang Ding. Thymic atypical carcinoid with cyclical Cushing's syndrome in a 7-year-old boy: a case report and review of the literature. Internal Medicine. 2014;4(5).

11. Manenschijn L, Koper JW, van den Akker EL, de Heide LJ, Geerdink $\mathrm{EA}$, de Jong FH, et al. A novel tool in the diagnosis and follow-up of (cyclic) Cushing's syndrome: measurement of long-term cortisol in scalp hair. J Clin Endocrinol Metab. 2012;97(10):E1836-43.

12. Gaur P, Leary C, Yao JC. Thymic neuroendocrine tumors: a SEER database analysis of 160 patients. Ann Surg. 2010;251(6):1117-21.

13. Jia R, Sulentic $P, X u J M$, Grossman AB. Thymic Neuroendocrine Neoplasms: Biological Behaviour andTherapy. Neuroendocrinology. 2017;105(2):105-14.

14. Haug AR, Cindea-Drimus $R$, Auernhammer $C J$, Reincke $M$, Wangler $\mathrm{B}$, Uebleis $\mathrm{C}$, et al.The role of $68 \mathrm{Ga}$-DOTATATE PET/CT in suspected neuroendocrine tumors. J Nucl Med. 2012;53(11):1686-92.

15. Virgolini I, Ambrosini V, Bomanji JB, Baum RP, Fanti S, Gabriel $M$, et al. Procedure guidelines for PET/CT tumour imaging with 68Ga-DOTA-conjugated peptides: 68Ga-DOTA-TOC, 68GaDOTA-NOC, 68Ga-DOTA-TATE. Eur J Nucl Med Mol Imaging. 2010;37(10):2004-10.

16. Papadakis GZ, Bagci U, Sadowski SM, Patronas NJ, Stratakis CA. Ectopic ACTH and CRH Co-secreting Tumor Localized by $68 \mathrm{Ga}$ DOTA-TATE PET/CT. Clin Nucl Med. 2015;40(7):576-8.

17. Sederberg-Olsen $P$, Binder $C$, Kehlet $H$, Neville AM, Nielsen LM. Episodic variation in plasma corticosteroids in subjects with Cushing's syndrome of differing etiology. J Clin Endocrinol Metab. 1973;36(5):906-10.

18. Albiger NM, Scaroni CM, Mantero F. Cyclic Cushing's syndrome: an overview. Arq Bras Endocrinol Metabol. 2007;51(8):1253-60.

19. Thorner MO, Martin WH, Ragan GE, MacLeod RM, Feldman PS, Bruni $C$, et al. A case of ectopic ACTH syndrome: diagnostic difficulties caused by intermittent hormone secretion. Acta Endocrinol (Copenh). 1982;99(3):364-70.

20. Mantero F, Scaroni CM, Albiger NM. Cyclic Cushing's syndrome: an overview. Pituitary. 2004;7(4):203-7.

21. Travis WD, Brambilla E, Nicholson AG, Yatabe $Y$, Austin JHM, Beasley MB, et al. The 2015 World Health Organization Classification of Lung Tumors: Impact of Genetic, Clinical and Radiologic Advances Since the 2004 Classification. J Thorac Oncol. 2015;10(9):1243-60.

22. Dinter $\mathrm{H}$, Bohnenberger $\mathrm{H}$, Beck J, Bornemann-Kolatzki K, Schutz E, Kuffer S, et al. Molecular Classification of Neuroendocrine Tumors of the Thymus. JThorac Oncol. 2019;14(8):1472-83.

23. Pelosi G, Pattini L, Morana G, Fabbri A, Faccinetto A, Fazio N, et al. Grading lung neuroendocrine tumors: Controversies in search of a solution. Histol Histopathol. 2017;32(3):223-41.

24. Soga J,YakuwaY, Osaka M. Evaluation of 342 cases of mediastinal/ thymic carcinoids collected from literature: a comparative study between typical carcinoids and atypical varieties. Ann Thorac Cardiovasc Surg. 1999;5(5):285-92.

25. Wick MR, Scott RE, Li CY, Carney JA. Carcinoid tumor of the thymus: a clinicopathologic report of seven cases with a review of the literature. Mayo Clin Proc. 1980;55(4):246-54.

26. de Perrot M, Spiliopoulos A, Fischer S, Totsch M, Keshavjee S. Neuroendocrine carcinoma (carcinoid) of the thymus associated with Cushing's syndrome. Ann Thorac Surg. 2002;73(2):675-81. 